\title{
Evaluation of a Teaching Programme about post myocardial infarction medications for nurses of coronary care units at Minia University Hospital and El-Amiry Hospital
}

\author{
Mahany , A., D ; Taha , N., M ; Elshfay , O., A; Gamal El-Dein , G., A . \\ Critical Nursing, Faculty of Nursing, Minia University, Egypt \\ Cardiology, Faculty of Medicine, Minia University, Egypt \\ Critical Nursing, Faculty of Nursing, Assuit University, Egypt \\ Adult Nursing, Faculty of Nursing, Minia University, Egypt
}

\begin{abstract}
:
The number of individuals diagnosed with myocardial infarction continues to increase; they are usually commenced on several long-term medications post-MI, Patient education regarding these medications is essential. Nurses play a vital role in educating MI patients, and as such, they themselves should be knowledgeable about what they teach. This study aimed to plan, implement, and evaluate the effect of a teaching program about post MI medications on nurses' knowledge. Subjects \& methods: An exploratory study was conducted to meet the aim of this study. This study was carried out in CCU in Minia University Hospital and in EL Amiry hospital. The sample included all nurses (33) in the two hospitals. Data were collected through using a questionnaire sheet included two parts: - Part I; included items related to sociodemographic characteristics, Part II; compromised 49 questions covering knowledge related to post myocardial infarction medications (aspirin, beta-blockers, an ACE inhibitors, and statins). Results of this study illustrated that The majority of nurses in both hospitals were females, work as bed side nurses \& have no previous training, also the study results revealed that in pretest (before conducting the teaching program) the majority of nurses of both hospitals (University hospital\& El Amery hospital) had unsatisfactory level of knowledge about post MI medications while in post test nearly all of them had satisfactory \& good knowledge level regarding theses medications (with high statistical significance difference $($ P.value $=0.000)$, total knowledge scores of nurses who were working in University hospital were significantly higher score than those who working at El Amery hospital (P.01) . also a significant relation was found between nurses' knowledge and their educational level. Conclusion of this study illustrated that the implementing of the teaching program about post MI medications (beta blockers, aspirin, ACE inhibitors and statins) was successful in improving and upgrading nurses' knowledge about these medications. Hospitals should recommend conducting a teaching program about post MI medications to MI patients.
\end{abstract}

\section{Key Words : Teaching Programme Post Myocardial Infarction Coronary Care}

\section{Introduction:}

Myocardial infarction (MI) commonly known as a heart attack is the irreversible necrosis of heart muscle secondary to prolonged ischemia. This usually results from an imbalance in oxygen supply and demand of the myocardium (Brieger, 2009). In the year 2003, it was estimated that heart attacks are the leading cause of death among both men and women all over the world. Cardiovascular diseases are the world's leading killer, accounting for 16.7 million or $29.2 \%$ of the total global deaths (Geneva, 2005). In the year 2007, WHO estimated that globally $29 \%$ of deaths were due to cardiovascular diseases and among them, 25-28\% of deaths were due to myocardial infarction (WHO, 2008).

All patients who have had an acute MI should be offered long term, often long life, treatment with a combination of the following drugs; ACE (angiotensin-converting enzyme) inhibitor, Aspirin,
Beta-blocker, and Statin unless a contraindication exists (NICE, 2007)\}. Each reduces the risk of recurrent cardiovascular events, hospitalizations, heart failure, and mortality in patients following MI. Each of these therapies individually has been demonstrated to have early as well as long-term benefits in patients presenting with MI (Mitaishvili, 2007). Taken in combination, these drugs have been estimated to reduce the relative risk of coronary heart disease CHD mortality by $80 \%$ as compared to placebo (Wald \& Law, 2003). Although Patients must adhere to their prescribed treatment regimens in order for these medications to maximally reduce the burden of (CHD), Poor adherence to post-MI medications has been documented. For example, only $45 \%$ of patients are fully adherent with beta-blockers in the $1^{\text {st }}$ year after an acute MI, and only $50 \%$ of patients are adherent with their prescribed statin. Less than $20 \%$ of acute MI patients use all the four 
recommended agents (beta blockers, statins, aspirin, and ACE inhibitors) in the $1^{\text {st }}$ year after an acute MI (Ramsay, et al, 2006).

Poor adherence to medication regimens in patients with heart failure and after myocardial infarction accounts for substantial morbidity and mortality. In retrospective reviews and small prospective studies, $33 \%$ to $69 \%$ of medication related hospital admissions were attributed to poor medication adherence (Osterberg \& Blaschke, 2005). Post-MI patients who discontinue their prescribed aspirin, statin, and beta-blocker are more likely to die three times than patients who remain adherent $(\mathbf{H o}$, et al, 2006). Medication nonadherence is associated with increased rates of hospital readmission, higher unnecessary progression of disease, and unnecessary development of preventable complications, diminished functional abilities, reduced quality of life, and premature death (Rockville, 2007).

Factors contributing to medication nonadherence include Lack of knowledge about the medication, Lack of adequate or effective patient instruction about the medications prescribed, including name, reason(s) for taking, what medication looks like, time(s) to take, how much to take, substances such as water or food to include versus avoid, possible side effects, what to do if side effects occur, how to manage any potential untoward effects, and ongoing self-testing Lack of time for patient counseling or follow-up Lack of reimbursement for time expended in patient education (Gadkari \& McHorney, 2010), (Brunton, 2011), and (Choudhry, et al, 2011). Nurses should take an active role in assessment, education, care planning, and strategic implementation efforts that support patients' optimal self-care behaviors and promote medication adherence (Albert, 2008). The roles of clinical nurses and physicians can be complementary, with nurses providing education to patients before discharge to promote greater medication adherence. The first several weeks of treatment are a critical time when many patients discontinue medications (Kramer, et al, 2006).

Patients need to be educated on their medications prior to discharge from the hospital, with nurses playing an intricate part in this process (Haynes, et al, 2008). Pocket cards can be used as a guide to help plan a medication program that meets patients' social needs and also prevents untoward adverse effects (Albert, 2007). Nurses need to know about all drugs a patient is taking. The nurse is responsible for using available current drug references to review unfamiliar data before administering the drug or instructing the patient to self administer the drug (Dian \& Samanta, 2006).
Medication knowledge was found to be unsatisfactory among practicing nurses, with a significant risk for medication errors. The study revealed a need to improve the nurses' basic knowledge, especially when referring to drug management (King, 2004). The recognition of the nurses' lack of knowledge, particularly in drug management, should be taken into consideration when revising the curriculum in nursing education, and training at work. The quality of existing courses may also be questioned, since courses are demonstrated to be of very small relevance to the knowledge. The institutions, who have legal responsibility for their employers' competence, should emphasize validation of both running and planned courses in medication topics. It is necessary to focus on both the content and regularity of medication courses, and consider some kind of certification for critical areas (Bjoerg, 2011).

Research has revealed the need for improved knowledge in medication knowledge (Banning, 2003). Educational programs are considered as a mean for providing nurses with theoretical and technical information needed to acquire new skills and to continually improve their nursing practice. Knowledge of the current recommendations for drug therapy, mechanism of action, adverse effects, precautions, and recommended dosing schedule allows nurses to collaborate with physicians about the patient's plan of care, educate patients and their families (Albert, 2007).

\section{The aims of the study:}

1. Assess nurses' knowledge in regarding to post myocardial infarction medications and identify the need for teaching program.

2. Develop a teaching program about post myocardial infarction medications.

3. Evaluate the program.

\section{Significance of the study:}

Most often doctors prescribe medications, pharmacist dispenses them, and nurses give them to patient. It means that nurses are usually in the front line when it comes to the patients and their drugs. It also means that nurses bear a major share of the responsibility for avoiding medication error. Also teaching the patient how to take drugs with the greatest efficiency and safety is often nurse's responsibility.

So the purpose of this study is to provide nurses with basic knowledge about post myocardial infarction medications in order to be able to provide effective educational intervention for patients with myocardial infarction about their medications that enable them to use their medications safely and effectively and increase their adherence to their drug therapy. For 
these reasons there is a clear need for more effective nurse education regarding post myocardial infarction medications.

\section{Subjects and Methods:}

Study design:Exploratory research design is used to fulfill the aim of this study.

Setting:The present study was conducted at the coronary care unit at Minia University Hospital \& Elamiry Hospital

Subjects: The study subjects consist of all nurses of coronary care unit (CCU) who are assigned to provide care for patients with myocardial infarction (MI) in CCU at Minia University Hospital \& Elamiry Hospital. They comprised 19 nurses at CCU in Minia University Hospital and 14 nurses at CCU in Elamiry Hospital.

Tool:

Tool 1: a questionnaire sheet: The overall purpose of this questionnaire was to assess nurses' knowledge about post MI medications. It was used in pre\& post test.

The questionnaire sheet included 2 parts:

Part 1: A demographic data sheet to obtain nurse's personal data. This included the age, sex as well as the education, residence, marital status, occupation and previous training.

Part 2: A Questionnaire sheet comprised questions related to knowledge about post MI medications (betablockers, ACE inhibitors, statins, and aspirin) was conducted to assess the need for educational programme and to evaluate it. So it was used two times before and after conducting the teaching program.

The teaching program: The following steps were adopted to develop the program: stating the program general and specific objectives, Planning the program: the content of the program were arranged into 2 educational sessions. The content of the program covered 4 related parts: Knowledge about Beta blockers medications, Knowledge about ACE inhibitors medications, Knowledge about Statins medications, and Knowledge about Aspirin medications.

Scoring system:

A scoring system for knowledge was developed based on clearly defined number of points.

Knowledge score was classified as follow: Good knowledge > 75\%, Satisfactory knowledge 50\%: $75 \%$, and Unsatisfactory knowledge $<50 \%$.

Ethical approval:

Each nurse was informed with the purpose of the study. The investigator emphasized that the participation is voluntary and confidentially and anonymity of subjects will be assured through coding of all data. Verbal consent was obtained from each nurse prior to his/her contribution in the present study. Confidentiality of any obtained information was secured.

\section{Methods:}

Study was conducted through:

- Tools development.

- An official permission was obtained from authorized administration, Faculty of Nursing, Manger of Minia University Hospital, head of (CCU) at Minia University Hospital, manager of Elamiry hospital and head of CCU at Elamiry hospital to collect data.

- At initial interview the researcher introduce herself to initiate communication, explain the nature and purpose of the study.

- Ask nurses to fill out the questionnaire sheet (tool I) to assess nurses` knowledge

- Each nurse involved in the study was assessed for his or her knowledge pre and post test (tool I). At initial interview the researcher introduce her self to initiate line of communication, explain the nature \& purpose of the study and fill out the interview sheet (tool I) to assess nurse's knowledge before application of the post MI teaching program. The tools filled through interviewing. The study was carried out at morning, and after noon shifts.

- Procedures: The study was carried out on three phases; First phase (pre test):This phase was carried out to assess nurses' knowledge about post MI medications with the purpose of determining their educational needs. To accomplish this phase a pretest was conducted using the study tool.Second phase: The phase of developing the program guided by nurses defined educational needs, pertinent literature and supervisors of the study. Third phase (post test): The phase of evaluating the program's outcomes: The same tool that had been used on the preprogram assessment was used to evaluate the program outcomes this phase was conducted one month after conducting the teaching program.

\section{Data analysis}

The collected data were reviewed, prepared for the computer process, coded, analyzed using statistical package for social sciences (SPSS) soft ware version 17 and tabulated. Chi-square tests were used to check the significance difference between frequencies before and after application of the teaching program. A significant $\mathrm{P}$ value was considered significant if less than 0.05 . 


\section{Results:}

Show that the majority of nurses in both hospitals (University \& El Amery) were females, work as bed side nurses \& have no previous training about post
MI medications. Also it revealed a statistical significant difference between nurses of the two hospital regarding age, education, and years of experience.

Table (1): total nurses' knowledge score level about post MI medications in pre\& posttest

\begin{tabular}{|c|c|c|c|c|c|}
\hline \multirow{2}{*}{$\begin{array}{c}\text { Test } \\
\text { Knowledge grade }\end{array}$} & \multicolumn{2}{|c|}{$\begin{array}{c}\text { Pre- test } \\
\text { total No. }=(19)\end{array}$} & \multicolumn{2}{|c|}{$\begin{array}{c}\text { Post }- \text { test } \\
\text { total No.= (19) }\end{array}$} & \multirow[t]{2}{*}{ P-value } \\
\hline & $\mathbf{N}$ & $\%$ & $\mathbf{N}$ & $\%$ & \\
\hline Unsatisfactory & 12 & 63.2 & 0 & 0 & \multirow{4}{*}{$0.0001 * *$} \\
\hline Satisfactory & 4 & 21 & 3 & 15.8 & \\
\hline Good & 3 & 15.8 & 16 & 84.4 & \\
\hline Total & 19 & 100 & 19 & 100 & \\
\hline
\end{tabular}

Figure (1): total nurses' knowledge score level about post MI medications in pre \& posttest in Elamiry hospital

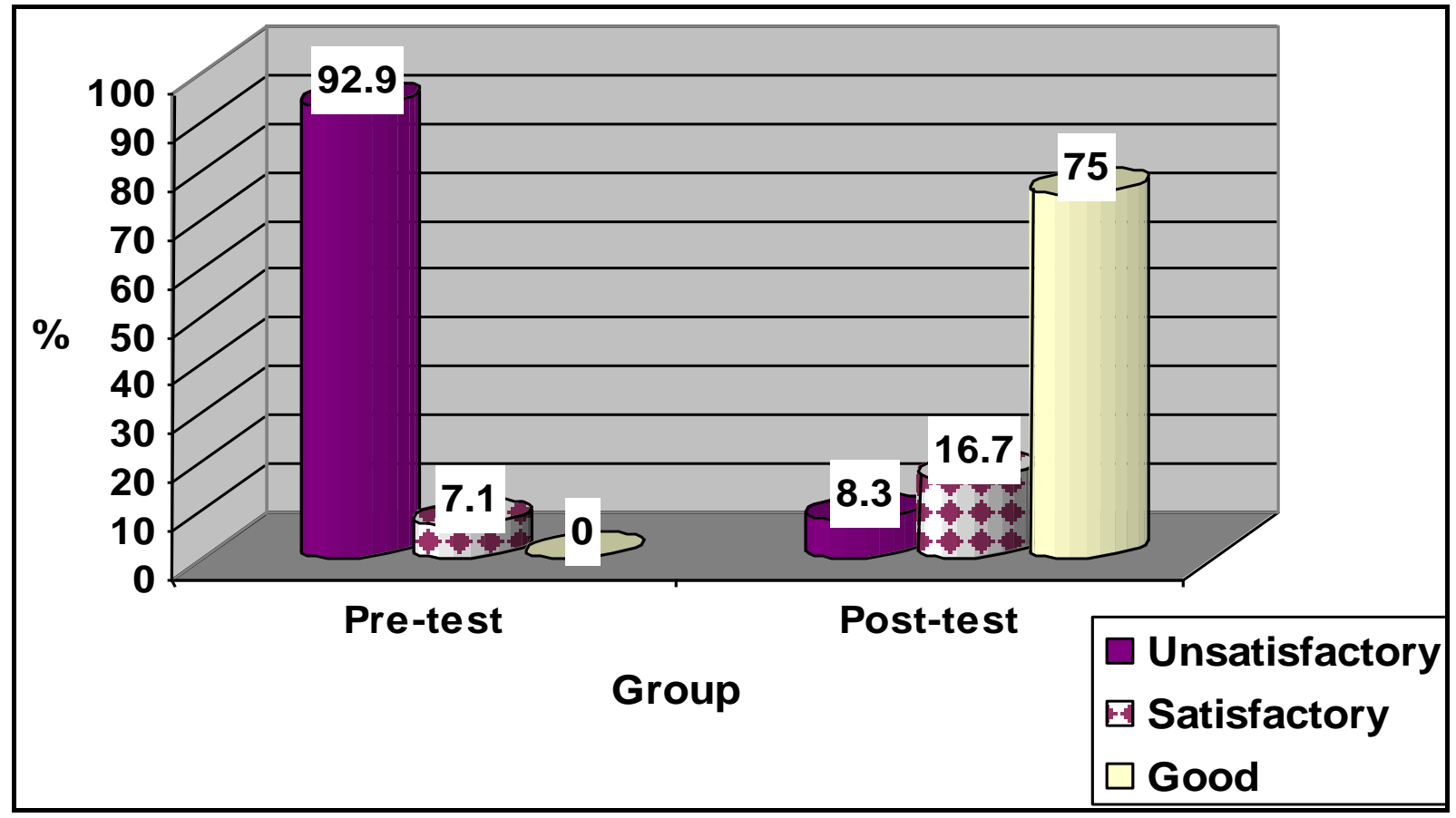

Table (2): Comparison between nurses' knowledge in University hospital \& in Elamiry hospital regarding post MI medications

\begin{tabular}{|c|c|c|c|c|c|}
\hline \multirow{2}{*}{$\begin{array}{l}\text { Hospital Nurses' } \\
\text { Knowledge grade }\end{array}$} & \multicolumn{2}{|c|}{ University hospital } & \multicolumn{2}{|c|}{ Elamiry hospital } & \multirow{2}{*}{$\mathbf{P}$} \\
\hline & $\mathbf{N}$ & $\%$ & $\mathbf{N}$ & $\%$ & \\
\hline Unsatisfactory & 12 & 63.1 & 13 & 92. & \multirow{4}{*}{0.01} \\
\hline Satisfactory & 4 & 21.1 & 1 & 7.1 & \\
\hline Good & 3 & 15.8 & 0 & 0 & \\
\hline Total & 19 & 100 & 14 & 100 & \\
\hline
\end{tabular}


Table (3): Relation between nurses' knowledge grade $\&$ their socio demographic data among nurses of both hospitals University hospital \& Elamiry hospital) in pre-test \& posttest

\begin{tabular}{|c|c|c|c|c|c|c|c|}
\hline \multirow{2}{*}{ Variables } & \multicolumn{6}{|c|}{ Knowledge grade } & \multirow{2}{*}{ P-value } \\
\hline & \multicolumn{2}{|c|}{ Unsatisfactory } & \multicolumn{2}{|c|}{ Satisfactory } & \multicolumn{2}{|c|}{ Good } & \\
\hline Sex & $\mathrm{N}$ & $\%$ & $\mathrm{~N}$ & $\%$ & $\mathrm{~N}$ & $\%$ & \multirow{3}{*}{0.4} \\
\hline Male & 4 & 100 & 0 & 0 & 0 & 0 & \\
\hline Female & 21 & 72.4 & 5 & 17.3 & 3 & 10.3 & \\
\hline \multicolumn{8}{|l|}{ Age } \\
\hline $18-28 y r s$ & 12 & 66.7 & 3 & 16.7 & 3 & 16.7 & \multirow[b]{3}{*}{.355} \\
\hline $29-38 y r s$ & 7 & 77.7 & 2 & 22.2 & 0 & 0 & \\
\hline$<38 \mathrm{yrs}$ & 6 & 100 & 0 & 0 & 0 & 0 & \\
\hline \multicolumn{8}{|l|}{ Residence } \\
\hline City & 8 & 72.7 & 2 & 18.2 & 1 & 9.1 & \multirow{3}{*}{0.8} \\
\hline Village & 10 & 71.4 & 2 & 14.3 & 2 & 14.3 & \\
\hline Governorate & 7 & 87.5 & 1 & 12.5 & 0 & 0 & \\
\hline \multicolumn{8}{|l|}{ Marital status } \\
\hline Married & 15 & 88.2 & 2 & 11.8 & 0 & 0 & \multirow{3}{*}{$0.01 *$} \\
\hline Single & 10 & 66.7 & 3 & 20 & 2 & 13.3 & \\
\hline Widow or divorced & 0 & 0 & 0 & 0 & 1 & 100 & \\
\hline \multicolumn{8}{|l|}{ Education } \\
\hline Faculty education & 3 & 33.3 & 4 & 44.5 & 2 & 22.2 & \multirow{3}{*}{$0.01 *$} \\
\hline Institute education & 9 & 90 & 0 & 0 & 1 & 10 & \\
\hline School education & 13 & 92.9 & 1 & 7.1 & 0 & 0 & \\
\hline \multicolumn{8}{|l|}{ Occupation } \\
\hline Head nurse & 1 & 50 & 1 & 50 & 0 & 0 & \multirow[t]{2}{*}{0.3} \\
\hline Nurse & 23 & 76.7 & 4 & 13.3 & 3 & 10 & \\
\hline \multicolumn{8}{|l|}{ Years of experience } \\
\hline$>5$ yrs & 12 & 80 & 2 & 13.3 & 1 & 6.7 & \multirow{3}{*}{$0.09(\mathrm{Ns})$} \\
\hline $5-10 \mathrm{yrs}$ & 4 & 44.4 & 3 & 33.3 & 2 & 22.2 & \\
\hline$<10 \mathrm{yrs}$ & 9 & 100 & 0 & 0 & 0 & 0 & \\
\hline \multicolumn{8}{|l|}{ Training } \\
\hline Yes & 0 & 0 & 1 & 100 & 0 & 0 & \multirow{2}{*}{0.440} \\
\hline No & 25 & 78.1 & 4 & 12.5 & 3 & 9.4 & \\
\hline
\end{tabular}

Regarding the relation between nurses' knowledge grade \& their socio demographic data (in post test) there_was a significant relation between nurses' knowledge and their age as nurses in age group from 18 to 28 years earned better knowledge than nurses of other age groups $(\mathrm{P}=.002)$.

Table (1) show that Most of nurses $(63.1 \%)$ in University hospital had unsatisfactory knowledge level in pre- test (before conducting the teaching program about post MI medications) while the majority of them (84.4\%) had good level of knowledge about post MI medications after conducting the teaching program. With high statistical significance $(\mathrm{p}$ value $=0.0001)$.

Figure (1) Shows that Nearly all of nurses in Elamiry hospital (92.9\%) had unsatisfactory level of knowledge in pre- test while the majority of them (75\%) had good level of knowledge about post MI medications in post test after conducting the teaching program. With high statistical significance $(\mathrm{p}$ value $=$ $0.0001)$.

Table (2) this table shows that, Total knowledge scores of nurses who were working in University hospital had significantly higher score than those who working at Elamiry hospital (P.01).

Table (3) Shows that, there_was a significant relation between nurses' knowledge and their marital status as single nurses had better knowledge than married ones, as single nurses having more time to read and to search about information than married ones . Also there_was a significant relation between nurses' knowledge and their level of education as baccalaureate degree nurses had better knowledge than diploma and technical institute nurses 


\section{Discussion:}

The discussion will cover the main result findings as follow:

I. Sociodemographic characteristics of nurses:

The results of the present study show that the majority of nurses in both hospitals (University \& Elamiry) were females, work as bed side nurses \& have no previous training about post MI medications. The study revealed a statistical significant difference between nurses of the two hospital regarding age, education, and years of experience, As the majority of nurses in University hospital were single, aging less than 28 years, graduated from faculty of nursing $\&$ technical $\mathrm{Ng}$ institute and most of them had less than 5 years of experience. While the majority of nurses in Elamiry hospital were married, have diploma (school nursing education), Most of them have more than 10 years of experience and less than half of them aging more than 38 years old.

П. Effect of implementing the teaching program on nurses' knowledge about post MI medications

The results of the present study as regards to nurses' knowledge about each drug, then totally about the whole four drugs and finally comparison between total nurses' knowledge in the two hospitals (University \& Elamiry) were stated as the following: Nurses' knowledge score about betablockers: Most nurses in University hospital \& the majority of nurses in Elamiry hospital had unsatisfactory knowledge level about beta blockers post MI medications) while all of them in University hospital $\&$ the majority of them in Elamiry hospital had good knowledge level in post test. With high statistical significance $($ P.value $=0.0001)$. This finding was agree with (Hsaio, et al., 2010) who found that nurses have insufficient knowledge about antihypertensive medications and could benefit from additional education. In this regard Albert et al, (2002) who stated that in order for effective patient education to take place the nurse needs an optimum knowledge. This foundation was emphasized by Nayak, et al, 2005 who found that the use of $\beta$ blockers increased from $57 \%$ to $98 \%$, in patients with coronary heart diseases following an educational intervention conducted by nurses joining educational program about cardiovascular medications.

Nurses' knowledge score about ACE inhibitors: Most nurses $(68.4 \%)$ in University hospital \& all nurses $(100 \%)$ in Elamiry hospital had unsatisfactory level of knowledge about ACE inhibitors medications in pre- test which decreased to $0 \%$ in University hospital \& $8.3 \%$ in Elamiry hospital in post test. With high statistical significance $(P$. value $=0.000)$. This finding supported by (Mallinson T., 2010) who found that nurses had poor knowledge regarding antihypertensive and their study demonstrated the need to provide more education on antihypertensive medications to nursing staff. In line with Washburn et al., 2005 signed out that since nurses are the main providers of patient education in a healthcare setting it is necessary that they, themselves, be knowledgeable. This was supported by Nayak, et al, 2005 who found that the use of angiotensinconverting enzyme inhibitors increased from 41 to $97 \%$, in apatients with coronary heart diseases following an educational intervention conducted by nurses joining educational program about cardiovascular medications.

Nurses' knowledge score about statins Most nurses in University hospital \& all nurses in Elamiry hospital had unsatisfactory knowledge level about statins medications( lipid lowering drugs) in pre- test while all of them in University hospital \& the majority of them in Elamiry hospital had good knowledge level in post test. With high statistical significance $(P . v a l u e=0.0001)$. In most healthcare facilities nurses are the key providers of any education the patient may need and will receive in the healthcare setting (Albert et al., 2002; Washburn, et al., 2005).As such, it is essential that the nurses providing such information be knowledgeable about what they are teaching. This is in line with Sanal $\&$ Aronow, 2003 stated that in patients with $\mathrm{CAD}$, the educational program increased the use of lipidlowering drugs by $36 \%$. This finding also supported by Fonarow, 2003 who found that Statin use was increased from $6 \%$ before initiation of the program to $86 \%$ after the Cardiovascular Hospitalization Atherosclerosis Management Program was implemented ( $\mathrm{P}<0.001)$. Also Karen, 2008 stated that Medication Therapy Management Program (MTMP) was successful in increasing statin use among members at high risk for cardiovascular (CV) events.

Nurses' knowledge score about aspirin: Most of nurses $(68.4 \%)$ in University hospital had good level of knowledge about aspirin medications in pre- test (before conducting the teaching program about post MI medications) which increased to (100\%) in post test, with statistical significance $(\mathrm{p}$ value $=0.028)$. While in Elamiry hospital most nurses $(\mathbf{6 4 . 3} \%)$ had unsatisfactory level of knowledge about aspirin medications (antiplatelet drugs) in pre- test, which decreased to $0 \%$ in post test, with high statistical significance $(\mathrm{P}$. value $=0.0001)$. This result agree with Rivet, 2012 who stated that After the education module, there was significant improvement in knowledge scores of CCU nurses in five of the eight survey questions, with performing the aspirin desensitization protocol. In this regards Millman, 2011 stated that Nurses who are knowledgeable in the 
topic they are teaching increase the chance that there are no misconceptions regarding that particular topic. This was in line with Nayak, etal, 2005 who found that the use of aspirin, increased from $69 \%$ to $99 \%$, in patients with coronary heart disease following an educational intervention conducted by nurses joining educational program about cardiovascular medications.

Finally total nurses' knowledge regarding the four post MI medications are significantly changed as most of nurses in University hospital \& The majority of nurses in Elamiry hospital had unsatisfactory knowledge level in pre- test (before conducting the teaching program about post MI medications) while the majority of them in the two hospitals had good level of knowledge in post test (P.value $=0.0001)$.

In pre test: As cleared from the above results this study show that Assessment of nurses' knowledge level before program implementation revealed that most nurses had unsatisfactory knowledge scores regarding all four post MI medications; Beta blockers, ACE inhibitors, statins and aspirin. This may be due to poor content in undergraduate nursing pharmacological courses in schools of nursing, technical institute of nursing and even faculty of nursing, absence of any educational programs about medications, and negligence of pharmacological aspects and patient drug teaching although they are crucial aspects of nursing care.

Among other factors attributed to lack of nurses knowledge; nurses' exhaustion, prolonged working hours and lack of incentives. This is supported by ( Teleb, 2001) \& (Emam, 2004) who stated that among factors contributed to lack of nurses knowledge is loss of enthusiasm due to lack of rewarding system and prolonged working hours. However Rivet, 2012 mentioned that it is essential to provide frequent education on infrequently performed protocols to ensure staff competence and comfort, as well as patient safety. Concerning the unsatisfactory nurses' knowledge results in pretest this finding is in accordance with (Washburn, 2005) who mentioned that nurses were not knowledgeable before participating in an education and communication intervention. The finding also agree with the study of BJoerg, et al., 2011 which shows that medication knowledge is unsatisfactory among practising nurses, with a significant risk for medication errors. And with West, 2010 who stated that the overall medication knowledge among registered nurses was lower than expected.

Regarding post test: From the above results this study show that the teaching program had great effect in improving the nurses' knowledge regarding post MI medications. These improvements were shown in both hospitals, at all ages, educational levels, experiences, and among staff and head nurses this was proven by the difference between pre $\&$ post program tests, which show high statistical significant differences in all 4 post MI medications. This relates to the clarity of the program material, using simple language and also high receptivity of the nurses, their interest, their need to acquire knowledge $\&$ increase self confidence.

In the same regards Bevis, 2003 stated that the nurse who has recognized that she had met the patient needs or perform a procedure using good techniques is not only a safe nurse but a confident one. This finding was supported by Emam, 2004 who reported that educational program has a good effect on improving the nurses' knowledge and performance. Also by Albert, 2008 \& Teleb 2001 who stated that nurses' knowledge would increase after attending educational programs. Agreed with Kraus, 2001 who found that there was a significant difference between the mean pretest score, and the mean posttest score, due to improvements in scores for the calculation questions. On the same line Fowler, 2012 who mentioned that education should target nurses' knowledge deficits and new knowledge of treatment and trends. also Westfall, et al., 2011 stated that inservice education programs are an effective method for inducing behavioral changes in nurses working in long-term care settings. These changes can improve the nurses' ability to monitor and promote safe and efficacious drug therapy in long-term care facilities.

As regards to the comparison between nurses' knowledge in the two hospitals (University \& Elamiry): the present study revealed that total knowledge scores of nurses who were working in University hospital had significantly higher than those who working at Elamiry hospital (P.01). This may be because nurses who work in University hospital had more resources, younger; most of them had baccalaureate degree in nursing. The finding is in accordance with the results of the study conducted by Emam, et al, 2004 who found that knowledge , attitude and practices of nurses who were working at University hospital were higher than those who working at Elamiry hospital . This also agree with (Abolwafa, 2009) who stated that knowledge scores of nurses who were working in University hospital had significantly higher than those who working in other studied hospitals (P.001). And also in line with results of (Mohammed, 2009) who found that the baseline mean scores for total and subtotal knowledge of nurses in University Hospital is higher than nurses in Elamiry Hospital and there is statistically highly significant $(0.001)$.

III. Relation between nurses' knowledge grade \& their socio demographic data: 
Regarding the relationship between nurses' knowledge and their age this study shows that nurses of age ranging from18-28yrs had better knowledge than nurses with age more than 28 years. This may be due to older nurses is more responsible for administrative and managerial activities, while younger ones have more practical work in direct patient care. This result disagree with Emam, 2004 who stated that the knowledge were slightly better among older nurses over the age of $30 \mathrm{yrs}$, compared to those, less than 30yrs regarding infection control. Regarding the relationship between nurses' knowledge and their educational level the present study revealed a significant difference between nurses' knowledge as regard to education ( $\mathrm{p}$. value $=$ 0.01). As baccalaureate degree nurses had higher knowledge scores than diploma and technical institute nurses. This may due to advancement of faculty curriculum. This finding was similar to the results of (Abolwafa, 2009, Gamal, 2005, (Hassan \& Aboulazm, 2007) \& Mohmmed 2009) who found that the total knowledge score of nurses having baccalaureate degree in nursing had significantly higher scores than those who having technical institute of nursing and those who having secondary nursing diploma. This finding disagreed with (Ali, 2010) who stated that technical institute nurses had significantly higher score than those who have baccalaureate degree of nursing, or those who have nursing diploma regarding infection control.

\section{Conclusion:}

Myocardial infarction patients require optimal nursing and medical care. The nursing staff that is assigned to care for MI patients requires continuous training in order to deliver an excellent patient care that leads to successful management of patient with MI. As MI Patients usually commenced on several long-life medications post-MI, with the aim of preventing secondary cardiovascular events such as congestive heart failure (CHF) and further myocardial infarctions. Such medications include aspirin, a beta-blocker, an ACE inhibitor, and a statin. Nurses must posse's knowledge about post myocardial infarction medications in order to be able to provide effective educational intervention for patients with myocardial infarction about their medications that enable them to use their medications safely and effectively and increase their adherence to their drug therapy.

The study results revealed that in pretest (before conducting the teaching program) the majority of nurses of both hospitals (University hospital \& Elamiry hospital) had unsatisfactory knowledge level regarding post MI medications (beta blockers - aspirin - ACE inhibitors- statins) while in post test nearly all of them had satisfactory \& good knowledge level regarding these medications (with high statistical significance difference).

Based on the results of the present study it can be concluded that the implementing of the teaching program about post myocardial infarction medications (beta blockers - aspirin - ACE inhibitors- statins) was successful in improving and upgrading nurses' knowledge about these medications.

\section{Recommendations:}

Based on results of the present study it can be recommended that:

- A teaching program about post myocardial infarction medications (aspirin - beta blockers statins- ACE inhibitors) should be conducted to myocardial infarction patients and to nursing internship students.

- Orientation training programs should be provided for nurses assigned to work in CCU with continuous education through work years.

- Establish a nursing library within the hospital and CCU supplied by recent textbooks, procedures, clinical cardiac pharmacology and also written booklets about MI medications.

- Nurses working with cardiac patients in CCU should be carefully selected according to their educational level. Nearly all CCU nurses should have baccalaureate degree nursing education.

- Curriculum of nursing pharmacology for faculty of nursing need to be revised and modified to stress on clinical pharmacology of such important cardiovascular medications.

\section{References:}

1. Abolwafa N F., (2009): Assessment of nurses' knowledge and performance related to infection control in the neonatal unites at El Minia city hospitals, PPs (83-85), thesis, Assuit University.

2. Albert N., Collier S., Sumodi V., et al., (2002): Nurses' knowledge of heart failure education principles. Heartand Lung, 31 (2), 102-112.

3. Albert NM, (2008): improving medication adherence in chronic cardiovascular diseases, CCNJ, 28 (5): 163-173.

4. Albert NM, Fonarow GC, Abraham WT, et al., (2007): Predictors of delivery of hospitalbased heart failure patient education: a report from OPTIMIZE-HF. J Card Fail.; 13: 189-198.

5. Ali M A., (2010): Assessment of nurses' knowledge and performance related to infection control precautions at Mallwy general hospital 
departments, PPs (93-97), thesis, Assuit University.

6. Banning M., (2003): Pharmacology education: a theoretical framework of applied pharmacology and therapeutics. Nurse Educ Today 2003, 23:459-466. PubMed Abstract.

7. Bevis S, (2003): Understanding the Complexity of Registered Nurse Work in Acute Care Settings. JONA, 33(22): 630-638.

8. Bjoerg O, Johansson I, Daehlin G, Osvik L, Farup P., (2011): Medication knowledge, certainty, and risk of errors in health care: a cross-sectional study. Arch Intern Med J, 157 (11): 99-104.

9. Brieger D, Kelly AM, Aroney C, Tideman P, Freedman SB, Chew D, Ilton M, Carroll G, et al., (2009): Acute coronary syndromes; consensus recommendations for translating knowledge into action; Med J Aust. 21;191(6):334-8.

10. Brunton S A., (2011): Improving Medication Adherence in Chronic DiseaseManagement. J Fam Pract; 60(4 suppl).

11. Choudhry NK \& Winkelmayer WC, (2008): Medication adherence after myocardial infarction: a long way left to go. J Gen Intern Med. 23:216-218.

12. Choudhry NK, Fischer MA, Avorn J, et al., (2011): The implications of therapeutic complexity on adherence to cardiovascular medications. Arch Intern Med. 2011; 171(9):814-822.Circulation, 107, 2227-2232.

13. Dian S \& Samanta J, (2006): Drug therapy in nursing, 2nd Edition, Lippicote William, PPs (4, 33).

14. Emam EA, Hassan SA, El - Mghazy D, and Mohamed NS., (2004): effect of educational program of paramedical's knowledge and attitude toward infection control in El Minia city hospitals. Doctorate Thesis, faculty of Nursing, Assuit University.

15. Fonarow GC., Gawlinski A., and Watson K., (2003): In-hospital initiation of cardiovascular protective therapies to improve treatment rates and clinical outcomes: the University of California-Los Angeles, Cardiovascular Hospitalization Atherosclerosis Management Program. Crit Path Cardiol. 2(2):61-70.

16. Fowler S, (2012): Improving Community Health Nurses' Knowledge of Heart Failure Education Principles: A Descriptive Study, Home Healthcare Nurse, 30 (2): 91 - 99.

17. Gadkari A \& McHorney C., 2010: Medication nonfulfillment rates and reasons for nonfulfillment: Narrative systematic review. Clin Ther. 2010; 26(3):683-705.
18. Gamal LM, (2005): establishing standards for prevention of nosocomial infection in the recovery rooms and surgical ward at El Minia University hospital, PPs (61- 63), thesis, Assuit University.

19. Geneva A., (2005): WHO recommended Prevention of heart diseases, JAMA, 293: 2865 2872.

20. Hassan H.E.K and Aboulazm S F., (2007): Infection control education in New Egyptian Journal of Medicine, 36(1): pp. 67:73.

21. Haynes RB, Ackloo E, Sahota N, et al., (2008): Interventions for enhancing medication adherence. Cochrane Database Syst Rev.; 16(2):CD000011.

22. Ho PM, Spertus JA, Masoudi FA, Reid KJ, Peterson ED, Magid DJ et al., (2006): Impact of medication therapy discontinuation on mortality after myocardial infarction. Arch Intern Med 166:1842- 1847.

23. Hsaio GY, Chen IJ, et al., (2010): nurses' knowledge on antihypertensive drugs, Journal of Advanced Nursing. Jan; 66(1) : 177-90.

24. Karen M. Stock I, Tjioe D, Gong S, MS, and Stroup J., (2008): Effect of an Intervention to Increase Statin Use in Medicare Members Who Qualified for a Medication Therapy Management Program. J Manag Care Pharm; 14(6):532-40.

25. Karen M. Stock I, Tjioe D, Gong S, MS, and Stroup J., (2008): Effect of an Intervention to Increase Statin Use in Medicare Members Who Qualified for a Medication Therapy Management Program. J Manag Care Pharm; 14(6):532-40.

26. King RL., (2004): Nurses' perceptions of their pharmacology educational needs, J Adv Nurs, 45:392-400.

27. Kraus D, (2001): Program to improve nurses' knowledge of pediatric emergency medications, American Journal of Health-System Pharmacy, 48(1): 97-101.

28. Mallinson T., (2010): "Myocardial Infarction". Focus on First Aid (15): 15 .

29. Millman F, (2011): Factors Associated with Nurses Practice Intention to Provide Heart Disease Risk and Prevention Education to Women Patients, thesis, Seton Hall University.

30. Mitaishvili MD, (2007): guidelines for management of post MI patients in outpatient setting, Circulation; 103:2768-2770.

31. Mohammed H E, (2009): Assessment of nurses' knowledge and intervention related to post stroke patients' rehabilitation in El Minia university hospital and El Minia general hospital, PPs (58 68), thesis, Assuit University. 
32. National Council on Patient Information and Education (NICE), (2007): Enhancing Prescription Medicine Adherence: A National Action Plan. Rockville, MD: National Council on Patient Information and Education.

33. Nayak M, Devraj D, Aronow M, and Wilbert S., (2005): Effect of an Ongoing Educational Program for nurses on the Use of Antiplatelet Drugs, [beta]-Blockers, Angiotensin-Converting Enzyme Inhibitors, and Lipid-Lowering Drugs in Patients with Coronary Artery Disease Seen in an Academic Cardiology Clinic, Cardiology in Review J; 13 (2): 95-97.

34. Osterberg L \& Blaschke T, (2005): Adherence to medication. N Engl J Med.; 353(5):487-497.

35. Quinn B, (2007): Pharmacological Treatment of Heart Failure, Critical Care Nursing Quarterly J, 30 (4): 299 - 306.

36. Ramsay SE, Whincup PH, Lawlor DA, et al, 2006: Secondary prevention of coronary heart disease in older patients after the national service framework: population based study. British Medical Journal. 332:144-145.

37. Rivet C., 2012: Desensitization training CCU RNs run aspirin desensitization project at The Miriam Hospital in Providence, J Am CollCardiol; 30:1606-1610.

38. Rockville MD., (2007): National Council on Patient Information and Education: Enhancing Prescription Medicine Adherence: Medication knowledge, certainty, and risk of errors in health care: a cross-sectional study, BMC Health Services Research 2011, 11:175.

39. Sanal $\mathbf{S} \&$ Aronow WS., 2003: Effect of an educational program on the prevalence of use of antiplatelet drugs, beta blockers, angiotensinconverting enzyme inhibitors, lipid-lowering drugs, and calcium channel blockers prescribed during hospitalization and at hospital discharge in patients with coronary artery disease. J Gerontol A Biol Sci Med Sci. 2003 Nov; 58(11):1046-8.

40. Smeltzer SC, Bare BG, Hinkle JL, Cheever KH., 2008: textbook of medical surgical nursing, $11^{\text {th }}$ edition, Lippicott Williams \& Wilkings, pp. 874- 883.

41. Teleb S M., (2001): Effect of an educational program about myocardial infarction on knowledge and performance of nurses, doctorate thesis, Assuit University.

42. Tsuyuki, et al., (2004): Improving the Use of ACE Inhibitors in Patients with Congestive Heart Failure: The Review of Education on ACE Inhibitors in Congestive Heart Failure Treatment (REACT) Study, Stage I. Alberta Journal of Cardiac Failure Vol. 10 No 62004.
43. Wald NJ \& Law MR, (2003): A strategy to reduce cardiovascular disease by more than $80 \%$. BMJ 326:1419.

44. Washburn SC, Hornberger CA, Klutman A, \& Skinner L., (2005): Nurses' knowledge of heart failure education topics as reported in a small Midwestern community hospital. Journal of Cardiovascular Nursing 20 (3), 215-220.

45. West CP, Shanafelt TD, Cook DA., (2010): Lack of association between resident doctors' well-being and medical knowledge. Med Educ 2010, 44:1224-1231.

46. Westfall LK, (2011): The effect of inservice education provided by consultant pharmacists on the behavior of nurses in long-term care facilities, Ann Pharmacother J; 145: 165-175.

47. World Health Organization, (2008): Adherence to long-term therapies: Evidence for action. 